\title{
Design, Fabrication, and Evaluation of a Village- Scale Yarning Machine
}

\author{
Feliciano G. Sinon
}

National Abaca Research Center, Visayas State University, Visca Baybay City, Leyte

\begin{abstract}
A multi-stranded yarning machine was designed to produce a material comparable with the "tinagak" yarn. The prototype was fabricated using locally available materials at NARC, VSU, Baybay City, Leyte. Modification activities were done to improve some perceived problems in the mechanical timing device, locking mechanism, and clutching assembly. Mechanism of the spooling assembly was also improved to allow easy joining of the synthetic yarn in case it breaks during the operation.

The improved prototype can produce 2 continuous abaca yarns simultaneously with lengths of 1.2 kilometer by wrapping around the abaca fiber with fine synthetic yarn. The yarn produced is also automatically arranged in the spool while a timing device automatically releases the locking rod when the yarn reaches 1.2 kilometer long.

Evaluation showed that an unskilled operator produces yarn at the rate of $380-430 \mathrm{~m} / \mathrm{h}$ at an efficiency of $80-95 \%$. A neatly woven product comparable to "sinamay" was produced from the multi-stranded yarn at the Matalom Abaca-Based Integrated Project (MABIP), Matalom, Southern Leyte.
\end{abstract}

Keywords: multi-stranded yarn, untwisted yarn, abaca yarn, tinagak yarn 
Design, Fabrication, and Evaluation of a Village-Scale Yarning Machine

\section{INTRODUCTION}

Abaca (Musa textiles Nee) is an industrial crop, which is native in the Philippines (Armecin, 2008). It contains a strong fiber known in the international market as "Manila hemp" (Anon, 1961; Ochi, 2006). The country supplies about $83 \%$ of the world fiber requirement while Ecuador, its main competitor, supplies about $17 \%$ only (FIDA 1984; Moreno and Canoy, 2000; Lacuna-Richman, 2002). Abaca fiber is a good material for the production of twine, ropes, cords, copra bags, grain sacks, hammocks coasters, placemats, doormats, rugs, hats, hot pads, etc. Because of its high tensile strength, tenacity, length, fineness, and durability under salt water condition (Sherman 1928; Sutermeister 1948; Villanueva 1972).

The processing of abaca into high valued products has been a traditional income generating activity in most abaca producing communities. It also adds value to the abaca fiber and helps augment the demand of abaca fiber in the local market (Yuhico 1975; Layese 1982). This activity has provided jobs for the people in the hinterlands and also prevented constituents to migrate and over-populate the cities (Castanares 1988).

Abaca yarn is the basic material for the production and processing of ropes, twines, cords, copra bags, grain sacks, hammocks coasters, placemats, doormats, rugs, hats, hot pads, etc. (Anon, 1973; Verino, 1974; Anon, 1975). Yarn can either be single, double, triple or even six strands of fiber bundle depending upon its desired use. It can also be twisted or nontwisted. Single fiber abaca yarn is made manually by knotting (sheet bend knot) the tip of the first fiber to the tip of the second, and so on; thus, it is not a twisted type of yarn (Baltazar 1930; NAI 1933).

In Bicol areas, woven products such as bags, rugs, hats, folding chair, etc. are made manually from twisted abaca yarn (Ejercito, 1929; Layese, 1982). It involves the following basic activities: yarn making (twisting of more than 5 strands of fiber), twine making (twisting together of 2 twisted yarns to produce small rope or twine), dyeing, loom weaving, and finishing (Baltazar, 1930; Anon, 1963). However, this type of multi-stranded yarn is of lower quality than the yarn produced by combining several singlestranded yarns together as in Bantig, Maasin, Leyte, because it produces more protruding fibers in the end products (Castanares 1988). Unfortunately, the process of producing untwisted multi-stranded yarn is still done manually (Ejercito 1929), thus it requires two steps: one is to form the single-stranded yarn (known as Tinagak) and the second is to 
combine several single-stranded yarns to form a multi-stranded yarn. This slow and boring work has discouraged young generations to continue, preferring to find jobs in the cities, leaving the older members of the community to continue the production. Hence, mechanization of the process is necessary to improve the production system (Castanares 1988).

This study aims to develop a yarning machine that will produce a multistranded untwisted yarn for the production of high valued abaca products.

\section{OBJECTIVES}

1. To design, fabricate, and evaluate a yarning machine for the production of multi-stranded-untwisted abaca yarn, and

2. To perform cost and return analysis of the developed machine

\section{MATERIALS AND METHODS}

\section{Actual Observation and Concept Generation}

Principle of yarn making known as "tinagak"(a Visayan term for singlestranded abaca yarn made by manually knotting the fiber) was observed through actual visit in Matalom, and Bantig, Maasin, Southern Leyte. Time and motion study was conducted to determine which particular part in the process is critical and requires mechanization.

Literatures related to yarning used in other hard fibers such as ramie, flax, hemp, etc. were reviewed. These were texts that came from the library and from the internet sources.

\section{Planning and Designing of a Yarning Machine}

The basic information obtained from the available literatures and the mechanical principle gained from the actual observation of the manual process was used as the basis in making the design concept of the machine. This was presented before a pool of engineers for comments, suggestions, and recommendations. The basis for judging were: workability, cost, output capacity, and availability of needed materials.

Design computations were conducted on the speed of the winding spool, sizes of the different transmission gears, distance of the wrapping synthetic yarn, and maximum length of the finished yarn. 


\section{Fabrication of the Prototype}

After gathering all the needed materials, fabrication of the machine was done at the National Abaca Research Center's fabrication shop. Important mechanisms of the machine component were fabricated first, followed by secondary components that support the main mechanism of the machine. The fabrication activity was completed by the assembling of the different machine components into the main frame.

\section{Testing and Evaluation of the Machine Prototype}

The machine prototype was subjected to testing and evaluation on its functionality and workability. Fabrication as well as design defects that affected the functionality of the entire system were carefully analyzed and corrected. As soon as the machine was working properly, this was subjected further to more testing and evaluation (Ahmad, Nawaz et al. 2004).

Yarning capacity of the machine was evaluated using three different operators at 20 minutes time for each trial to operate the machine, to make a single multi-stranded abaca yarn. The length of the yarn produced per trial was measured and the machine capacity was computed which is equal to the length of yarn produced per unit time.

$$
C=\frac{L}{t}
$$

$$
\text { Where: } \begin{aligned}
C & =\text { machine capacity } \\
& L=\text { length of yarn }(\mathrm{m}) \\
& t=\text { time }(\mathrm{h})
\end{aligned}
$$

Operator's efficiency was based on the actual time the machine was used to produce yarn divided by the total time the machine was running per trial multiplied by 100 .

$$
E_{o p}=\frac{t_{a}}{t_{t}}
$$

Where: $\mathrm{E}_{\mathrm{op}}=$ operator's efficiency

$\mathrm{t}_{\mathrm{a}}=$ actual time, $(\mathrm{min})$

$\mathrm{t}_{\mathrm{t}}=$ total tile, $(\mathrm{min})$ 
Functionality and Workability Evaluation of the Yarning Machine

Functionality and workability of the machines' mechanisms were tested and evaluated for a longer time period. However, due to unavailability of combed fiber, testing and long runs were done even without the raw materials just to observe how the different parts of the machine functioned and to test whether the timing and locking systems worked properly.

\section{Modification of the Spooling Lock and Timing Device}

Modification of the spooling lock and timing device was done to simplify the spool locking system, to prevent its potential malfunctioning. This resulted also to the modification of the timing device.

\section{Production ofCombed Abaca Fiber}

Since the efficiency of the yarning process using the machine is greatly affected by the type of fiber materials especially if they are crumpled and short, a village-level abaca-combing machine was also fabricated to produce loose abaca fibers as raw material for yarn production. The machine has two main components: the combing assembly and the feeding assembly. The combing assembly is made of lumber with trapezoidal cross section. These are attached with nail spikes protruding vertically up at 2.5 $\mathrm{cm}$ in length. The terminal ends of the lumbers are bolted on the two flat belts. The set of lumbers with spikes look like a conveyor belt running over a wooden slatted flat pulley.

A bundle of $S_{2}$ fiber, about $3 / 4 \mathrm{~kg}$ was clipped into the fiber holder located at the feeding assembly of the combing machine. After securing the fiber, the rope holding the clip was wounded fully to the free-wheeling direction by rotating the pulley manually. The technique of putting the clip at its starting point prevents over feeding of the fiber into the combing machine which may cause the motor to be overloaded as too much resistance will be encountered in separating the whole section of the fiber bundle. The $3 / 4 \mathrm{~kg}$ of fiber bundle was effectively loosened by the combing machine at about 1 minute time. This was used as raw materials for the yarn production. 
Design, Fabrication, and Evaluation of a Village-Scale Yarning Machine

Production of Multi-stranded Yarn and Pilot Production of "sinamay" from Multi-stranded Yarn

The developed multi-stranded yarning machine was used in the production of yarns using the loosed abaca fiber. The individual fiber was fed into the rotating funnel-hopper of the yarning machine and as the tip of the last fiber was about to end, another set of fiber was again fed into the hopper. This was done with a short overlapping of the fiber to make it stable, stronger, and continuous.

About 2 kilograms of abaca multi-stranded yarn was brought to MABIP, Matalom, Southern Leyte for testing on the possibility and quality of the material for sinamay production. Comments were taken from the weaver after the product was finished.

\section{RESULTS AND DISCUSSION}

\section{Analysis of "tinagak" making process}

Result of the study on "tinagak" production in Matalom, Leyte showed that only sheet bend knot can be applied in the process to prevent the fiber from being folded. Since the cross section of individual fiber bundle is made up of 40 to 80 fiber cells of about 5 to $10 \mathrm{~mm}$ long bonded together by cementitios material known as lignin, when the fiber bundle is folded its strength is reduced by about 40 to $60 \%$ (Sinon 2008). Tinagak making involves four major steps: pulling off the loosed fiber, knotting the fiber tips "head to tail", cutting the fiber tips, and dropping the finished yarn (Guzman, Mangalindan et al. 1998). Knotting represents 30\% only of the whole process by skilled tinagak makers. One kilogram of tinagak yarn can be finished by 1 person in 1 week time.

\section{Design Considerations of the Yarning Machine}

Designing of village-scale knotting machine has been considered a very difficult solution to the present problem. Commercial knotting tool for textile used at the Philippine Textile Research and Training Center (PTRI) did not work for abaca fiber. The fibers were broken during the knotting process. Several designs did not also work, and proposed design was not also fabricated due to in-availability of precision equipment (Pelesco and Dominguez 2005). 
The result of the deliberations with the pool of engineers used to develop a village scale alternative. Instead of producing a single-fiber yarn product, a multi-stranded yarn has to be produced, to make it more attainable. This is achieved through wrapping the abaca fiber with a fine synthetic fiber. The design considerations for the yarning machine were: peripheral speed of the spooling reel should be $6 \mathrm{~m} / \mathrm{min}$ or $10 \mathrm{~cm} / \mathrm{sec}$; this is based on the normal speed capacity of operator to feed the fiber. Desired RPM of the feeding funnel is $2.5 \mathrm{rev} / \mathrm{sec}$ or $150 \mathrm{rev} / \mathrm{min}$ to obtain wrapping distances of $4 \mathrm{~mm}$ of the spooled yarn. The binding fiber should be fine, colorless, and strong; this should wrap around the abaca fiber to keep them together. There should be a mechanism to temporarily stop the operation in case there are entangled fibers or during stock ups, and it must be controlled by a foot pedal. The desired length should be uniform so that there will be no difficulty in putting two filaments together during the process of twine making. There should be a counter or an automatic lock when the desired length is reached.

Computations of the different sizes of gears, transmission belts and pulley system, design of lock system, mechanism for pedal clutch, spooling and wrapping mechanism were done and the overall view of the machine and the detailed mechanical components were drawn at the National Abaca Research Center (Fig. 1).

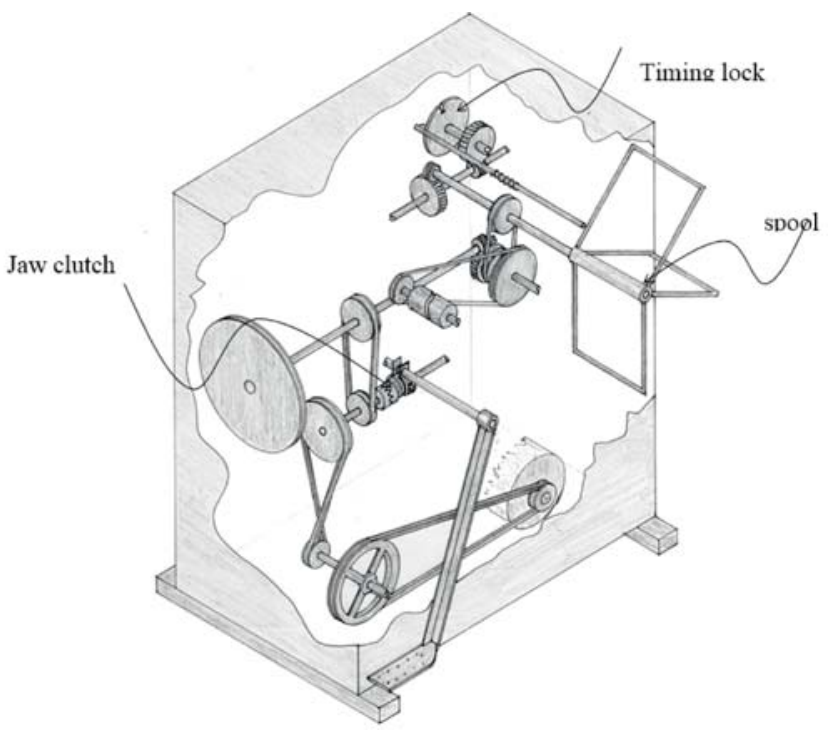

Figure 1. Working mechanism of the designed multi-stranded yarning machine 
Design, Fabrication, and Evaluation of a Village-Scale Yarning Machine

\section{Fabrication of the Yarning Machine Prototype}

A prototype of an abaca multi-stranded yarning machine was fabricated using locally available materials (Fig. 2). The machine is $63.5 \mathrm{~cm}$ long, $63.5 \mathrm{~cm}$ wide and stands at $76.2 \mathrm{~cm}$ high. The total mass of the machine is approximately $60 \mathrm{~kg}$. The machine is powered by a single-phase $1 / 4 \mathrm{Hp}$ electric motor, transmitted using belt and pulley, and gear system. The timing device is activated by a compression spring and is run by the chain and sprocket transmission system.

The machine is composed of four major working components: power transmission mechanism, feeding and wrapping funnel, spooling reel, and timing mechanism. The power transmission mechanism is specifically composed of the power source, transmission pulleys and belts, and clutching component. The jaw-type clutch component allows the operation to temporarily stop in case of stock-ups when the pedal provided below the feeding funnel is stepped down, disengaging the clutch system. The clutch-pedal is also provided with a spring-controlled lock that activates when the pedal is fully pressed downward. The feeding and wrapping funnel is where the raw fiber is feed. The rotating feeding funnel is attached with a bobbin that contains very fine fiber that wraps around the abaca fiber as it is spooled into the spooling reel.

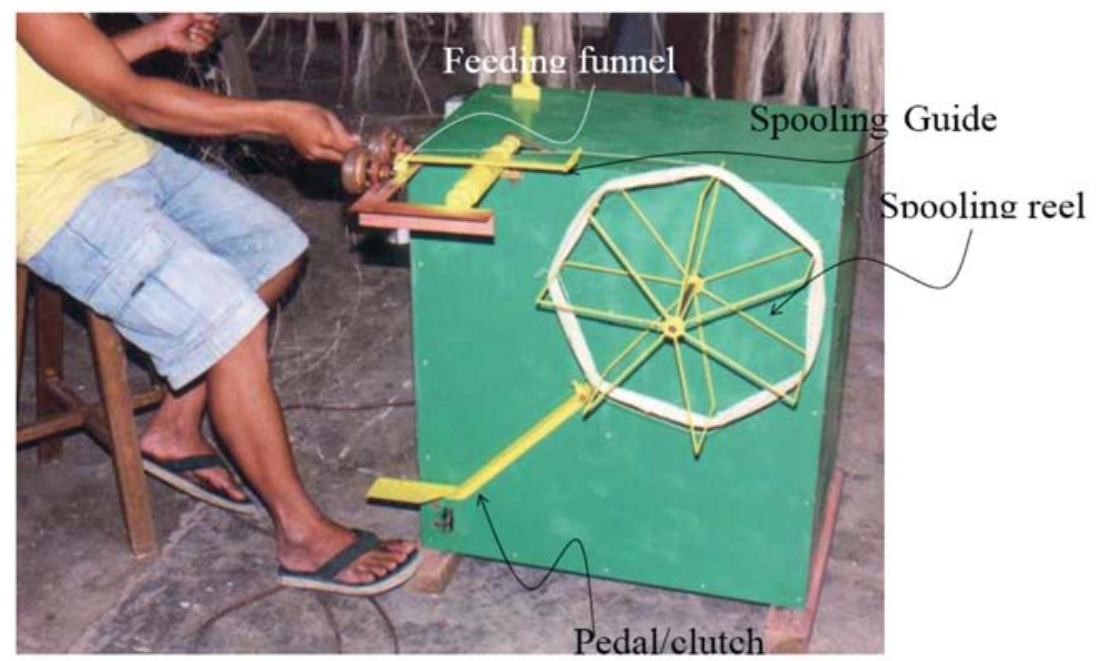

Figure 2. The multi-stranded yarning machine in operation 
To operate, two to three strands of fiber are tied into the spooling reel together with the fine polyester yarn and these are made to pass in the holes provided for in the guide bar and the feeding funnel. When the switch is on, the spooling mechanism starts to pull the fiber and wraps it around the reel while the feeding funnel that houses the bobbin containing the very fine polyester yarn wraps and joins the abaca fiber together. The next set of individual fiber is then fed to the feeding funnel and so on and so forth to join the fibers together and to make a long continuous yarn. When the length of the yarn reaches $100 \mathrm{~m}$ the timing device automatically locks up and the operation is halted.

\section{Preliminary Production of Twine}

After several modifications in the different machine components, preliminary testing of the machine showed that all the machine components worked well and properly. It was observed that the machine can produce a maximum of two 100 meters of abaca yarn in 12 minutes or at the yarning rate of about 1,000 meters an hour (this theoretical capacity can only be attained with a highly skilled operator and the availability of very loose and combed fiber).

Preliminary production of two types of twines from the two multistranded yarns made from nylon and polyester yarns as binding materials showed different characteristics. The twine produced using nylon binder had a brownish but shining color; that of the polyester twine showed a natural white color effect with the abaca fiber. However, in the polyester twine some fine hairs or protruding polyester fiber can be seen in the product.

\section{Modifications Done on the Machine}

\section{a.) Clutch's engage and disengage mechanism}

The original design (Fig. 3) of the clutch's engage and disengage mechanism was found to have a potential problem in the long run. It was observed that in order to disengage as the desired yarn length is reached, the spring in the locking rod system should over power the spring in the clutching system so it works properly. This means that in the long run, when the spring weakens, the clutch engage and disengage system will not work. 


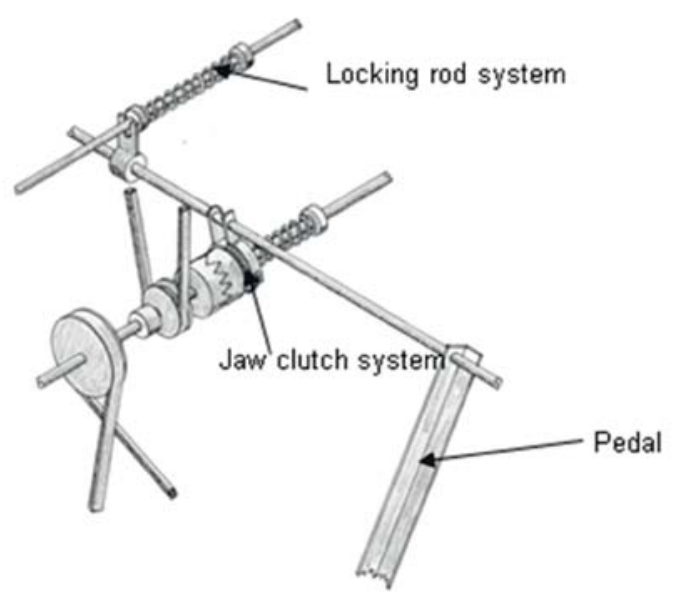

Figure 3. Original design for stopping the machine through disengaging the clutch system.

\section{b. Transmission system to effect reverse rotation}

Modification of the machine was done on the transmission mechanism connecting the spool and the timing device. This was done to simplify the locking mechanism of the timing device as well as to make the rotation of the spooling wheel reversible. The reducing worm gear (Fig. 4.A) directly connected to the shaft of the spooling wheel was removed and relocated from the top to the bottom side of the driving worm gear where another shaft was added (Fig. 4.B). Then additional shaft then was attached with a 5 $\mathrm{cm}$ pulley to drive the similar-sized pulley attached at the shaft of the spooling wheel. The additional belt and pulley system give the possibility of the spool to be rotated manually in reverse direction due to slippage.

\section{c. Timing mechanism}

The timing cam system and locking rod that activates to lock the pedal clutch was removed. Another set of worm gear was added to activate the timing device not only to increase the length of yarn produced by the machine from 100 to $1,000 \mathrm{~m}$ but also to reposition the timing cam, thereby allowing the locking rod to lock directly on the spooling wheel instead of the pedal clutch. This simplifies the timing device and locking system. Moreover the locking rod only needs weaker compression spring to be 
activated.

The four different positions (Fig. 5) of the original locking and timing mechanism; A) Temporary lock engaged, B) the cam pushes the temporary lock after half cycle of the plate, C) lock transfer to the pin located at the tip portion of the rod, and D) rod engaged pushes the spring of the clutch system to disengage.
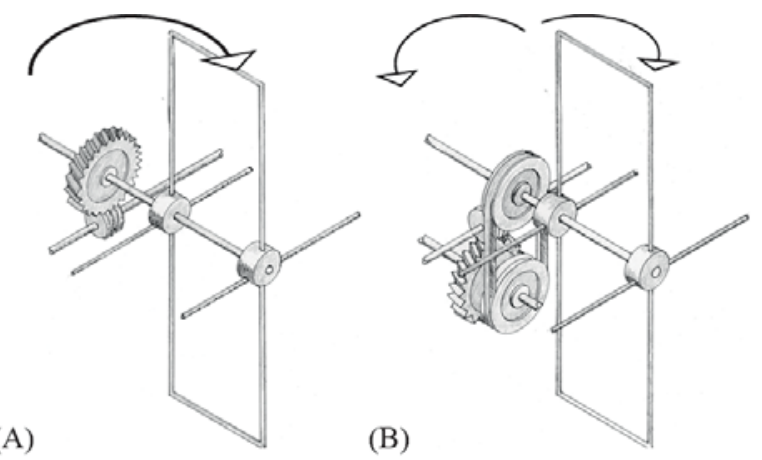

Figure 4. (A) Original gear arrangement (B) New arrangement with addition of belt and pulley transmission system to effect reverse-rotation by manual-turning.
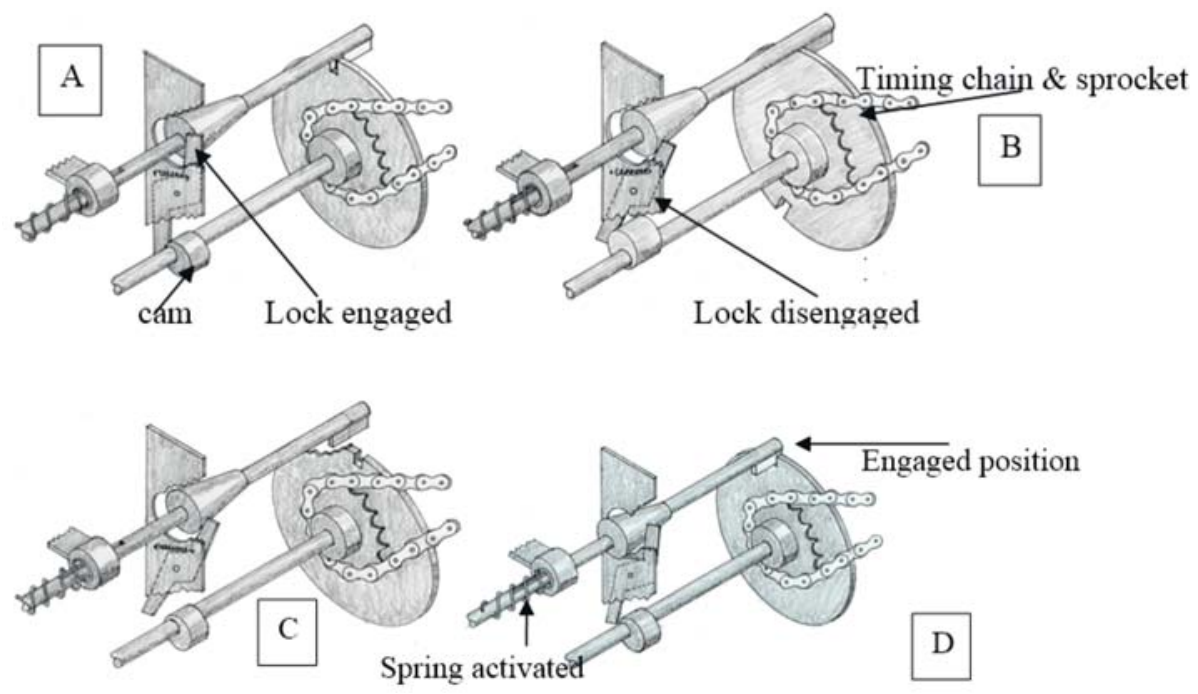

Figure 5. Original design of the timing mechanism 
Figure 6 shows the new design of the timing and lock mechanism. A) Initial position where the pin/key is blocked by the temporary lock, B) soon as the whole cycle of the timing plate is made, the temporary lock is pushed sideway by the pin thereby engaging the lock system.

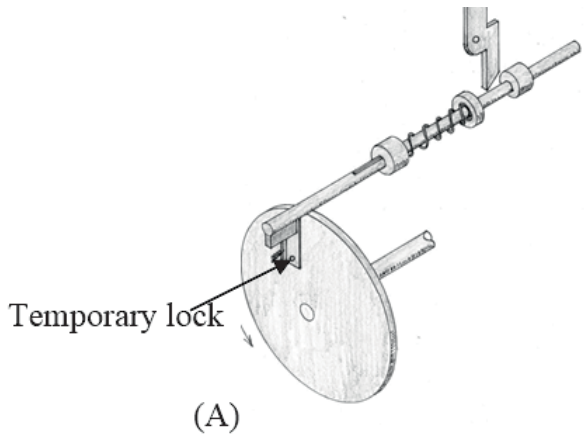

Figure 6. New design of the timing and lock mechanism.

\section{Yarning Capacity Evaluation}

After the machine improvement and modification, the yarning machine prototype was subjected to yarning capacity evaluation. Combed Lalay fiber with an approximate average length of $1 \mathrm{~m}$ was used. Three operators were requested to operate the machine at three replications.

Table 1 shows the result of the capacity evaluation of the yarning machine prototype as operated by three different operators. There was no significant difference observed on the capacity and operators efficiency of the machine. The average yarning capacity of the machine was $410 \mathrm{~m} / \mathrm{h}$ with an average efficiency of $88 \%$ (using single yarn). Considering that the operators were unskilled at the time of evaluation and they did one yarn at a time, a skilled operator who can make two yarns at a time using the machine, he can potentially double his output to about $800 \mathrm{~m} / \mathrm{h}$.

Table 1. Yarning machine capacity evaluation operated by three different operators.

\begin{tabular}{lcc}
\hline Operators & $\begin{array}{c}\text { Yarning Capacity } \\
(\mathrm{m} / \mathrm{h})\end{array}$ & $\begin{array}{c}\text { Operators Efficiency }(\%) \\
\text { single yarn }\end{array}$ \\
\hline Operator 1 & 432.37 & 95.22 \\
Operator 2 & 375.20 & 81.44 \\
Operator 3 & 421.60 & 87.99 \\
Mean & 409.72 & 88.22 \\
c.v. & 8.32 & 9.07 \\
\hline
\end{tabular}




\section{Evaluation of different bindingyarns}

To determine the average length of multi-stranded yarn produced per length of the binding material, this was taken using 10-meter length of binding/wrapping materials (Table 2). Tinagak averages $8.60 \mathrm{~m}$ of yarn, $8.99 \mathrm{~m}$ for sewing machine thread and $11.33 \mathrm{~m}$ for the polyester yarn. The high stretchability of the polyester material could be the main factor that yarn produced using this binder that could reach up to $15 \%$ more than its original length.

Table 2. Length of multi-stranded yarn produced from 10-meter length of different wrapping/binding materials.

\begin{tabular}{lcccc}
\hline Types of Yarn & $\begin{array}{c}\text { Trial 1 } \\
(\mathrm{m})\end{array}$ & $\begin{array}{c}\text { Trial 2 } \\
(\mathrm{m})\end{array}$ & $\begin{array}{c}\text { Trial 3 } \\
(\mathrm{m})\end{array}$ & $\begin{array}{c}\text { Mean } \\
(\mathrm{m})\end{array}$ \\
\hline Machine-Tinagak & 8.54 & 8.42 & 8.85 & 8.60 \\
Machine-Thread & 8.97 & 8.95 & 9.05 & 8.99 \\
Machine-Polyester & 11.10 & 11.40 & 11.50 & 11.33 \\
\hline
\end{tabular}

Evaluation of timing mechanism

The maximum length of yarn produced by the developed yarning machine after modification was determined through a series of trials using its new timing mechanism. Without stopping (Table 3.), the machine averages $3 \mathrm{~h}$ and $4 \mathrm{~min}$ to complete 1 -rotation of the timer with average length of yarn of 1,218 meter or $1,220 \pm 1 \%$.

Table 3. Total length of yarn produced and total counter time of the multi-stranded yarning machine.

\begin{tabular}{lcc}
\hline Trials & $\begin{array}{c}\text { Time } \\
(\text { hr:min })\end{array}$ & $\begin{array}{c}\text { Length } \\
(\mathrm{m})\end{array}$ \\
\hline T1 & $3: 3$ & 1,210 \\
T2 & $3: 3$ & 1,220 \\
T3 & $3: 6$ & 1,228 \\
Mean & $3: 4$ & 1,216 \\
\hline
\end{tabular}

\section{Costand return analysis}

Table 4 lists the assumptions used for the computation of the cost and return for the production of multi-stranded yarn and the "tinagak" yarn. 
Design, Fabrication, and Evaluation of a Village-Scale Yarning Machine

\section{Production of combed abaca fiber}

Production of combed abaca fiber was found necessary for the evaluation and production of multi-stranded yarn. Preliminary evaluation of the combing machine showed that the machine has combing capacity of about $2 \mathrm{~kg}$ per hour which may be enough to supply 16 units of yarning machine. There were some factors observed that affected the fiber recovery in the combing machine such as variety, degree of crumpling, length, maturity, and dryness. Combing capacity is also dependent on several factors such as: length of the fiber, degree of crumpling, and pretreatment done on the fiber.

Functionality testing of the yarning machine and production of different designs of multi-stranded yarn

After some improvements and modifications of the machine components, pre-testing was done to observe its functionality. It was also observed that after some modifications and improvements, the wrapping distances of the polyester to the abaca fiber were already closer resulting to a neatly made multi-stranded continuous yarn with only minimal protruding fibers.

Different multi-stranded yarns were also produced using different colors of polyester materials (Fig.7). Some products were fancy and some showed potential in terms of uniqueness and attractiveness. It can be noted that with the availability of different polyester yarn materials, different product designs can be obtained with the combinations of different colors.
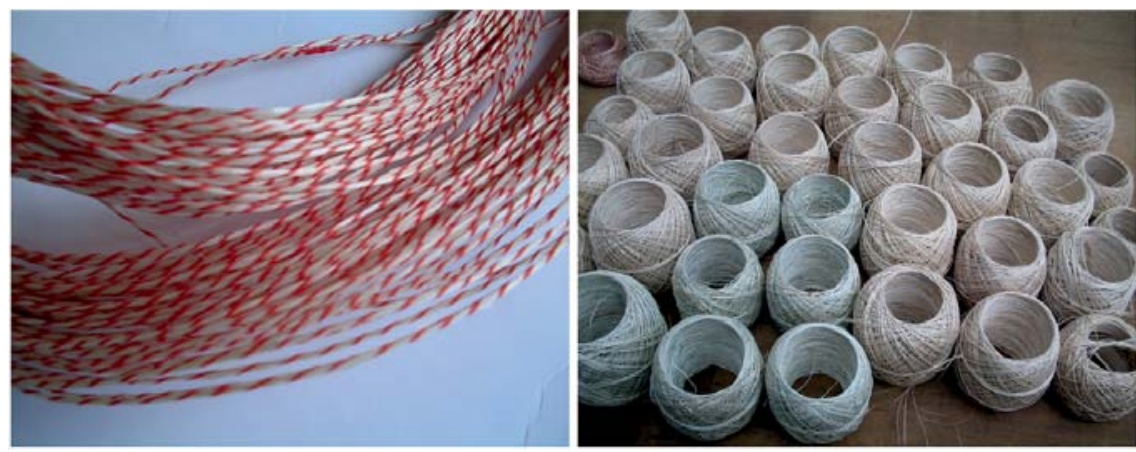

Figure 7. Different yarn products developed using the yarning machine. 
Table 4. Assumptions for the cost and return for multi-stranded yarn and tinagak yarn.

\begin{tabular}{lcc}
\hline \multicolumn{1}{c}{ Assumptions } & Tinagak Yarn & Multi-stranded \\
\hline Electric motor $(\mathrm{Hp})$ & none & $1 / 4$ \\
Depreciation cost $(\mathrm{PhP})$ & none & 5,000 \\
Life span (yrs) & none & 15 \\
Loan Interest (\%) & none & 20 \\
Tax, insurance (\%) & none & 2 \\
Operation per day (hrs) & 8 & 8 \\
Power consumption (kW-hr) & none & 1.34 \\
Price of escujedo fiber (PhP) & 60 & 60 \\
Capacity (kg/day) & 0.02 & 2.4 \\
\hline
\end{tabular}

Table 5 below shows that the yarning machine has a daily net income of P232, a payback period of less than a year, and a return on investment of $165 \%$. On the other hand, the manual tinagak production has a negative net income considering that one person can only produce 1 kilo in a week if labor cost is $\mathrm{P} 150$ and his production is only worth $\mathrm{P} 60 /$ day.

Table 5. Cost and return analysis of producing tinagak yarn in comparison with the yarn produced by the yarning machine.

\begin{tabular}{lcc}
\hline \multicolumn{1}{c}{ Criteria } & Tinagak Yarn & Multi-stranded \\
\hline 1. Annual Fixed Cost (P) & - & $4,169.33$ \\
2. Cost per day (P) & 152.00 & 391.76 \\
3. Cost per hr (P) & 19.00 & 48.97 \\
4. Gross Income/day (P) & 60.00 & 624.00 \\
5. Net Income (P) & $(190)$ & 232.24 \\
6. Payback period (yrs) & - & 0.608 \\
7. Return on Investment (\%) & - & 165.88 \\
\hline
\end{tabular}

\section{Pilot testing of theyarning machine}

The multi-stranded yarning machine prototype was brought to MABIP in Matalom, Leyte for pilot testing. The potential operators were requested to familiarize and operate the machine. Comments and suggestions were also solicited from the different operators regarding the machine's workability, functionality, and usefulness. All the operators gave positive comments. There was also one particular comment on the clutch pedal i.e. make it easier to unlock. Operators seemed to have some difficulty in unlocking the pedal clutch; this was probably due to their 
Design, Fabrication, and Evaluation of a Village-Scale Yarning Machine

unfamiliarity on the machine resulting to the frequent use of the pedal clutch. The produced yarn was then tested on the weaving loom to produce sinamay product (Fig. 8). Some observations on the use of the multistranded yarn given by the sinamay maker in MABIP are as follows:

1. The weaver expressed ease in the use of the yarn because it had very low resistance during weaving and did not break.

2. Weaving was very smooth. This could be due to the polyester material which wrapped around the soft and smoother fibers; this could be due to the waxes in the surfaces of the abaca fiber obtained during the combing process.

3. The woven product was very neat and clean.
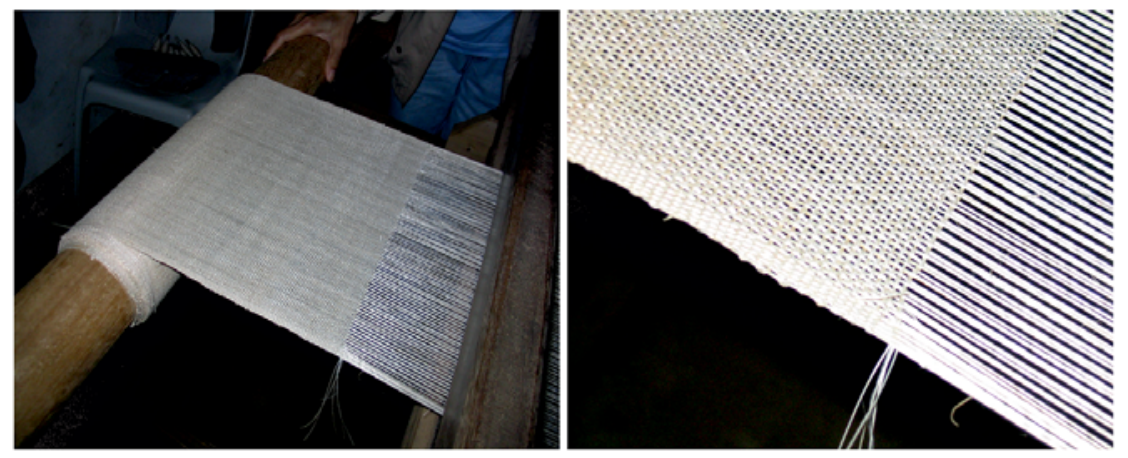

Figure 8. Neatly woven sinamay from the multi-stranded abaca yarn.

\section{CONCLUSION AND RECOMMENDATIONS}

This study has shown that a yarning machine suitable for village-scale application can be designed and fabricated using locally available materials. Modification and improvement activities on different machine assembly and parts can improve the overall operation of the machine system to produce multi-stranded yarn more efficiently. Different fancy yarn products can also be produced by the machine using different binding materials such as cotton thread, polyester, and nylon.

Furthermore, this study also shows that operating the machine can have a payback period of less than one year and a Return on Investment (ROI) of 167\%. Meanwhile, using the "tinagak" making process produced negative net income due to the slow and drudgery of the knot tying technique. 
It is recommended that pilot-testing of the machine prototype shall be conducted in other abaca producing communities in the country to promote the availability of the machine and to determine the peoples acceptance of the technology.

Further testing on the use of other binding materials such as silk and other natural fibers shall be conducted.

A twining machine should be developed to process the multi-stranded yarn into twine produced by the yarning machine to complete the system.

\section{REFERENCES}

AHMAD, I., S. M. NAWAZ and M. TAYYAB. 2004. Interaction Study of Staple Length and Fineness of Cotton with Ultimate Yarn Regularity and Hairiness Journal of Applied Sciences 4(1): 48-52.

ANON 1961. Abaca in North Borneo. Cordage Canvas Jute World 436(495): 24-27.

ANON 1963. Mass production of abaca products. Agric Ind Life 25(10): 17.

ANON 1973. Preparation for making rope and for fiber selling. Fiber Ind Cordage World 38(443): 22-25.

ANON 1975. The many uses of abaca. Abaca Spec Bull 1(4): 1.

ARMECIN, R. B. 2008. Nutrient Composition of Abaca (Musa textilis Nee) at Seedling, Vegetative, and Flagleaf Stages of Growth. Journal of Natural Fibers 5(4): 331-346.

BALTAZAR, E. P. 1930. Twine and sack-making as a possible home industry in the Philippines Islands. Philipp Agric 11(1): 26.

CASTANARES, J. M. 1988. The economics of abaca fibercrafts in Bantig, Maasin, So. Leyte. A case study. Dept Ag, ViSCA, Baybay, Leyte: 29p. 
Design, Fabrication, and Evaluation of a Village-Scale Yarning Machine

EJERCITO, J. M. 1929. The knotted hemp industry of Indang, Cavite. Philipp Agric Rev 22(1): 71-74.

FIDA 1984. Profile of the Philippine abaca industry. Quezon City, Fiber Industry development Authority: 1-182.

GUZMAN, Z. I., N. B. MANGALINDAN, E. M. MARTIN and M.S de LEON. 1998. Development of Philippine tropical fabrics from indigenous sources. Philippine Technology Journal 23(2): 1-21.

LACUNA-RICHMAN, C. 2002. The role of abaca in the household economy of a forest village. Small-scale Forest Economics, Management and Policy 1(1): 93-101.

LAYESE, G. F. 1982. Fibercraft industry in the Bicol region. Symposium on abaca research and devlopment, Legaspi City, FIDA 1983.

MORENO, L. O. and R. CANOY 2000. Benchmark survey on the status of the abaca industry in Southern Leyte. Leyte State University, Baybay City, Leyte: 230.

NATIONAL ANALYST INCORPORATED 1933. Farmers-opinion and practices among manufacturers of cordage and twine. USDA Market Research report 31: 104.

OCHI, S. (2006). Development of high strength biodegradable composites using Manila hemp fiber and starch-based biodegradable resin. Composites Part A: Applied Science and Manufacturing 37(11): 18791883.

PELESCO, V. A. and R. DOMINGUEZ (2005). Design and Development of Tinagak Knotting Machine. Southern Leyte State University, Sogod, Southern Leyte: Terminal report. 25p.

SHERMAN, P. L. (1928). "The tensile strength of abaca fibers in relation to their acidity." Philipp J Sci 37(1):21-33.

SINON, F. (2008). Optimization of stripping technologies for the production of high quality abaca fiber. Institute of Agricultural Engineering for the Tropics and Sub Tropics. Stuttgart, Shaker Verlag. 
SUTERMEISTER, E. 1948. Fibrous raw materials. Manila hemp. New York, John Wiley and Sons, Inc.

VERINO, G. A. 1974. The cordage industry. Proceedings of the National Workshop Seminar on Abaca Production, UPLB, College, Laguna.

VILLANUEVA, E. P. 1972. Processing abaca fibers into a high yield bleached pulp. Forpride Dig 1(2): 38-39.

YUHICO, D. N. 1975. A feasibility study on the manufacture of handicrafts in Albay for exports., Asian Institute of Management, Makati, Metro Manila: 70p. 